the TONADO ${ }^{\oplus}$ studies did not show a significant difference in the hazard ratios for time to exacerbation end points. These findings are partially attributable to a higher number of severe exacerbations with T/O $5 / 5 \mu \mathrm{g}$ in TONADO ${ }^{\oplus} 1$. TONADO ${ }^{\circledast}$ was not designed for formal comparison of exacerbations with $\mathrm{T} / \mathrm{O}$ versus $\mathrm{T}$; however, a study powered to assess this is ongoing.

Funding Boehringer Ingelheim.

Please refer to page A273 for declarations of interest in relation to abstract P296.

\section{P297 LUNG-FUNCTION PROFILE BEFORE AND AFTER THE FIRST MODERATE TO SEVERE EXACERBATION DURING THE WISDOM STUDY}

${ }^{1} \mathrm{E}$ Wouters, ${ }^{2} \mathrm{H}$ Magnussen, ${ }^{3} \mathrm{R}$ Rodriguez-Roisin, ${ }^{4} \mathrm{~K}$ Tetzlaff, ${ }^{5} \mathrm{~S}$ Bell, ${ }^{6} \mathrm{PM}$ A Calverley. ${ }^{1}$ Department of Respiratory Medicine, University of Maastricht, Maastricht, the Netherlands; ${ }^{2}$ Pulmonary Research Institute at Lung Clinic Grosshansdorf, Airway Research Centre North, German Centre for Lung Research, Grosshansdorf, Germany; ${ }^{3}$ Servei de Pneumologia, Hospital Clínic IDIBAPS-CIBERES, Universitat de Barcelona, Barcelona, Spain; ${ }^{4}$ Boehringer Ingelheim Pharma GmbH and Co. KG, Ingelheim, Germany; ${ }^{5}$ Department of Biometry and Data Management, Boehringer Ingelheim, Bracknell, UK; ${ }^{6}$ Institute of Ageing and Chronic Disease, Aintree University Hospital, Liverpool, UK

\subsection{6/thoraxjnl-2016-209333.440}

Rationale The WISDOM study (NCT00975195) showed no increased risk of exacerbation when inhaled corticosteroid (ICS) was withdrawn stepwise in patients with severe COPD on LAMA +LABA maintenance therapy versus continued LAMA+LABA + ICS. ${ }^{1}$ Daily home spirometry measured the time course of lungfunction changes throughout the study. The aim of this post hoc analysis was to address the lung-function profile leading up to, during and following the first moderate-to-severe exacerbation.

Methods WISDOM was a multinational, randomised, doubleblind study. ${ }^{1}$ Patients with severe to very severe COPD entered a 6-week run-in with LAMA+LABA+ICS (tiotropium $18 \mu \mathrm{g}$ once daily; salmeterol $50 \mu \mathrm{g}$ twice daily; fluticasone propionate $500 \mu \mathrm{g}$ twice daily), and were randomised to continue LAMA+LABA +ICS or salmeterol/tiotropium for 52 weeks while discontinuing ICS in a stepwise manner over 12 weeks. On-treatment daily forced expiratory volume in 1 second $\left(\mathrm{FEV}_{1}\right)$ change from baseline was calculated before and after the first moderate-to-severe exacerbation. In this post hoc analysis, we included patients who experienced a moderate-to-severe exacerbation after the ICSwithdrawal visit, did not have an exacerbation in the 8 weeks before or after the exacerbation, and had daily home-measured $\mathrm{FEV}_{1}$ data available for every week analysed.

Results Of 2488 patients, 262 experienced a moderate-to-severe exacerbation after the ICS-withdrawal visit and had lung-function data for every week. For all patients combined (ICS and ICS withdrawal), change in $\mathrm{FEV}_{1}$ remained relatively stable 56-14 days before the first moderate-to-severe exacerbation (mean $\mathrm{FEV}_{1}$ change from baseline values: -0.04 to $-0.07 \mathrm{~L}$ ) (Figure). There was a decline in lung function starting 2-3 weeks before exacerbation $\left(\mathrm{FEV}_{1}\right.$ change value of $-0.12 \mathrm{~L}$ from baseline), followed by a moderate improvement over $\sim 14$ days. Post-exacerbation lung function did not reach pre-exacerbation levels.

Conclusions Lung function was relatively stable in both treatment groups. Home spirometry measurements showed a marked decline in $\mathrm{FEV}_{1}$ prior to moderate-to-severe exacerbation with improvements seen post-exacerbation, although not to pre-exacerbation levels. These findings support the usefulness of home

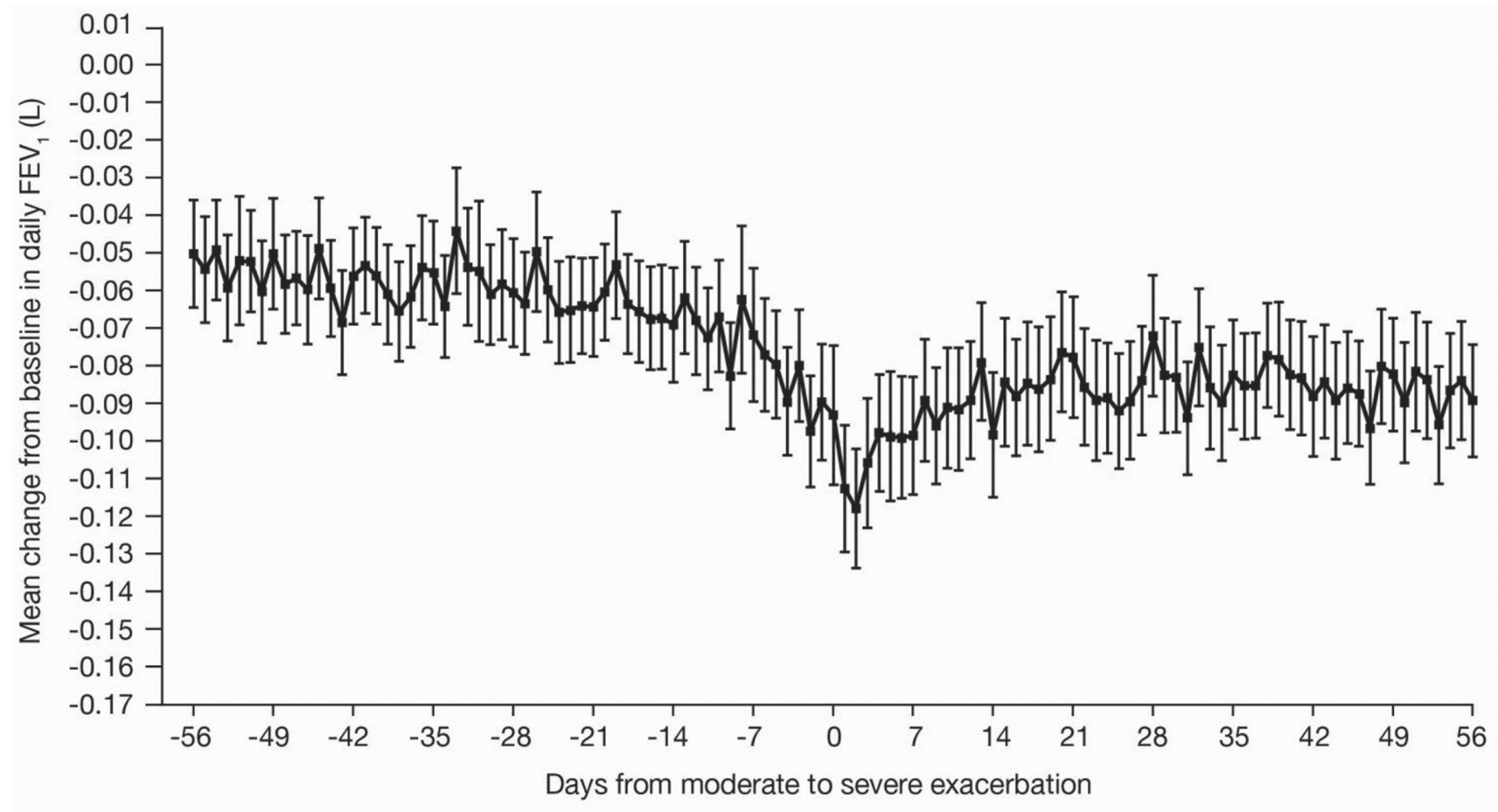

Plot includes patients whose first moderate to severe exacerbation after the ICS-withdrawal visit was neither preceded by an exacerbation of any severity in 8 weeks prior nor followed by a further exacerbation of any severity within 8 weeks ( 56 days) after Note that Day 0 is the day of the exacerbation

Abstract P297 Figure 1 Mean change from baseline in on-treatment daily FEV 1 before and after first moderate to severe exacerbation for both treatment combined. 
spirometry to predict exacerbations and to indicate subsequent worsening of lung function resulting from a previous COPD exacerbation.

Funding Boehringer Ingelheim.

Please refer to page A273 for declarations of interest in relation to abstract P297.

\section{REFERENCE}

1 Magnussen $\mathrm{H}$, et al. N Engl J Med 2014;371:1285-1294.

\section{P298 TIOTROPIUM/OLODATEROL THERAPY PROVIDES SYMPTOMATIC BENEFITS IRRESPECTIVE OF PRIOR MAINTENANCE TREATMENT: POST HOC ANALYSES OF THE OTEMTO ${ }^{\circledR}$ STUDIES}

${ }^{1} \mathrm{R}$ Abrahams, ${ }^{2} \mathrm{GT}$ Ferguson, ${ }^{3} \mathrm{~L}$ Bjermer, ${ }^{4} \mathrm{~L}$ Grönke, ${ }^{4} \mathrm{~F}$ Voß, ${ }^{5} \mathrm{D}$ Singh. ${ }^{1}$ Morgantown Pulmonary Associates, Morgantown, USA; ${ }^{2}$ Pulmonary Research Institute of Southeast Michigan, Farmington Hills, USA; ${ }^{3}$ Department of Respiratory Medicine and Allergology, Lund University, Lund, Sweden; ${ }^{4}$ Boehringer Ingelheim Pharma GmbH and Co. KG, Ingelheim, Germany; ${ }^{5}$ The Medicines Evaluation Unit, Manchester, UK

\subsection{6/thoraxjnl-2016-209333.441}

Rationale The combination of tiotropium (T), a long-acting muscarinic antagonist (LAMA), plus olodaterol $(\mathrm{O})$, a long-acting $\beta_{2}$ agonist (LABA), is approved for once-daily maintenance treatment of COPD. The randomised, double-blind, Phase IIIb OTEMTO $^{\circledast 2} 1$ and 2 studies (NCT01431274; NCT01431287) showed improvements in quality of life and lung function after 12 weeks' treatment with T/O compared to T alone or placebo in patients with moderate to severe COPD. This post hoc analysis investigated whether previous maintenance treatment with a long-acting bronchodilator or inhaled corticosteroid (ICS) influenced symptomatic benefits of $\mathrm{T} / \mathrm{O}$.

Methods Patients aged $\geq 40$ years received T/O 2.5/5 $\mu$ g, T/O 5/5 $\mu \mathrm{g}$, T $5 \mu \mathrm{g}$ or placebo once daily for 12 weeks via Respimat inhaler. St George's Respiratory Questionnaire (SGRQ) total score was a primary end point, alongside lung function $\left(\mathrm{FEV}_{1}\right.$ area under the curve from $0-3$ hours and trough $\mathrm{FEV}_{1}$ responses). Secondary end points included Mahler Transition Dyspnoea Index (TDI) focal score. Salbutamol/albuterol was provided as rescue medication and use was recorded in an e-diary. We report comparisons between $\mathrm{T} / \mathrm{O} 5 / 5 \mu \mathrm{g}, \mathrm{T} 5 \mu \mathrm{g}$ and placebo. Results Of the 1621 patients evaluated, 943 had received prior maintenance treatment (66.7\% LABA; 59.4\% LAMA; 64.5\% ICS) and 678 had not. Similar improvements in mean SGRQ total score were observed with $\mathrm{T} / \mathrm{O}$ compared to $\mathrm{T}$ and placebo, respectively, in patients receiving prior maintenance treatment $(-2.02$ and -4.59 units) and those without $(-2.20$ and -4.78 units) (Table). TDI focal scores improved with T/O compared to $\mathrm{T}$ and placebo, respectively, in patients receiving prior maintenance treatment ( 0.60 and 1.87 units) and those without $(0.60$ and 1.33 units) (Table). Patients with and without prior maintenance treatment demonstrated similar improvements in daytime and night-time rescue medication use and lung-function improvements with $\mathrm{T} / \mathrm{O}$ compared to $\mathrm{T}$ and placebo.
Conclusions $\mathrm{T} / \mathrm{O}$ provides symptomatic benefits as demonstrated by improvements in SGRQ score, TDI focal score and decreased rescue medication use compared to placebo and $T$, independent of previous maintenance treatment. These findings suggest $\mathrm{T} / \mathrm{O}$ is beneficial over monotherapy when used as first COPD maintenance treatment.

Funding Boehringer Ingelheim.

Please refer to page A273 for declarations of interest in relation to abstract P298.

\begin{tabular}{|c|c|c|}
\hline $\begin{array}{l}\text { Treatment } \\
\text { comparison }\end{array}$ & $\begin{array}{l}\text { Prior maintenance } \\
\text { treatment }\end{array}$ & $\begin{array}{l}\text { No prior maintenance } \\
\text { treatment }\end{array}$ \\
\hline \multicolumn{3}{|l|}{ SGRQ total score } \\
\hline T/O $5 / 5 \mu \mathrm{g}$ - placebo & $-4.59(-10.23,1.06)$ & $-4.78^{* *}(-6.93,-2.63)$ \\
\hline $\mathrm{T} / 05 / 5 \mu \mathrm{g}-\mathrm{T}$ & $-2.02(-5.42,1.37)$ & $-2.20^{*}(-4.34,-0.07)$ \\
\hline \multicolumn{3}{|l|}{ Mahler TDI focal score } \\
\hline $\mathrm{T} / 05 / 5 \mu \mathrm{g}-$ placebo & $1.87^{* *}(1.36,2.39)$ & $1.33^{* *}(0.76,1.90)$ \\
\hline $\mathrm{T} / 05 / 5 \mu \mathrm{g}-\mathrm{T}$ & $0.60^{*}(0.09,1.10)$ & $0.60^{*}(0.04,1.17)$ \\
\hline
\end{tabular}

Adjusted mean (95\% confidence interval) ${ }^{* *} p<0.001,{ }^{*} p<0.05$

\section{P299 EFFECTS OF SYMPTOM SEVERITY AT BASELINE ON LUNG-FUNCTION AND SGRQ RESPONSES IN THE OTEMTO ${ }^{\circledR}$ STUDIES}

${ }^{1} \mathrm{FJ}$ Martinez, ${ }^{2} \mathrm{R}$ Abrahams, ${ }^{3} \mathrm{GT}$ Ferguson, ${ }^{4} \mathrm{~L}$ Bjermer, ${ }^{5} \mathrm{~L}$ Grönke, ${ }^{5} \mathrm{~F}$ VoB, ${ }^{6} \mathrm{D}$ Singh. ${ }^{1}$ Pulmonary and Critical Care Medicine, Cornell Medical College, New York, USA; ${ }^{2}$ Morgantown Pulmonary Associates, Morgantown, USA; ${ }^{3}$ Pulmonary Research Institute of Southeast Michigan, Farmington Hills, USA; ${ }^{4}$ Department of Respiratory Medicine and Allergology, Lund University, Lund, Sweden; ${ }^{5}$ Boehringer Ingelheim Pharma GmbH and Co. $K G$, Ingelheim, Germany; ${ }^{6}$ The Medicines Evaluation Unit, Manchester, UK

\subsection{6/thoraxjnl-2016-209333.442}

Rationale In the randomised, double-blind, Phase IIIb OTEMTO $^{\oplus} 1$ and 2 studies (NCT01431274; NCT01431287), the combination of tiotropium (T), a long-acting muscarinic antagonist, plus olodaterol $(\mathrm{O})$, a long-acting $\beta_{2}$-agonist, showed meaningful improvements in quality of life (St George's Respiratory Questionnaire [SGRQ]) and lung function in patients with moderate to severe COPD after 12 weeks' treatment compared to T alone or placebo. This post hoc analysis investigated whether symptomatic status at inclusion, as measured by the modified Medical Research Council (mMRC) dyspnoea scale and the Baseline Dyspnoea Index (BDI), influenced lung-function and SGRQ responses.

Methods Patients aged $\geq 40$ years received T/O 2.5/5 $\mu$ g, T/O 5/5 $\mu \mathrm{g}$, T $5 \mu \mathrm{g}$ or placebo once daily for 12 weeks via Respimat ${ }^{\boxplus}$ inhaler. SGRQ total score and lung function $\left(\mathrm{FEV}_{1}\right.$ area under the curve from $0-3$ hours $\left[\mathrm{AUC}_{0-3}\right]$ and trough $\mathrm{FEV}_{1}$ responses) were primary end points. Patients completed the $\mathrm{mMRC}$ and BDI scales at baseline. We report comparisons between $\mathrm{T} / \mathrm{O} 5 / 5$ $\mu \mathrm{g}, \mathrm{T} 5 \mu \mathrm{g}$ and placebo. 